\title{
COVID-19 and Depression of College Student: A Literature Review
}

\author{
Yinxin Ding ${ }^{1, \dagger, *}$, Junyi Hong ${ }^{2, \dagger, *}$, Yuebin Zhang ${ }^{3, \dagger, *}$ \\ ${ }^{1}$ Newcastle University, Newcastle Upon Tyne, United Kingdom \\ ${ }^{2}$ University of Melbourne, Victoria, Australia \\ ${ }^{3}$ New York University, New York, United States \\ ${ }^{*}$ Corresponding author.Email: honjh@student.unimelb.edu.au
}

These authors contributed equally.

\begin{abstract}
The global COVID-19 pandemic has had a significant impact on the mental health of college students. This article introduces several main reasons why college students may have a psychological crisis when facing the COVID-19 crisis: economic factors, distance learning and racism. The possible solutions and their feasibility are discussed from the perspectives of universities, society, and individuals. The discussion of this issue may provide guidance for government policies and how individuals respond to the COVID-19 crisis in the era of pandemic.
\end{abstract}

Keywords: Depression, Pandemic, College, Literature review, Policy, Individual

\section{INTRODUCTION}

Recently, the world is in the shadow of novel coronavirus or what is known as coronavirus disease 2019 (COVID-19), which has been stated as a global pandemic. Governments in all countries have implemented strict public health measures to contain the outbreak and minimize severe illness and deaths. In the environment of lockdown, private institutions and higher educational institutions are affected to the maximum extent possible. These institutions have to halter their activities and change their classes from in-person to online. Therefore, with the spread of COVID-19, nationwide closures have impacted over $91 \%$ of the world's student population who can't attend school life [1]. The epidemic has led to a gradual tendency of depression and even depression among remote learning college students who encounter many challenges [2]. Charissa et al(2020)'s survey on the depression index of college students shows that the regional incidence of COVID and the depression index of college students are positively correlated [3]. Students who have suffered from depression for a long time usually perform poorly in academic performance and stress management, and have a higher possibility to have depression disorder which may cause some negative impacts on individuals and society [4]. Therefore, it is necessary to discuss the relationship between coronavirus and depression of college students. This article aims to explore the changes in the degree of depression among college students since the new coronavirus pandemic and propose possible solutions. This essay will first explain the background of the significant issue raised recently: the increased number of depression in college students during the COVID-19. Then, based on a literature review of other research and journal articles, the reasons for this issue will be discussed. During the pandemic, a great number of college students are experiencing lockdown and remote learning problems. It might bring a negative effect on their mental health. Additionally, COVID-19 brings up stereotypes that lead to racism among Chinese students and will make students feel unsupported and discriminated against. Furthermore, the epidemic leads to financial problems among families, making college students face more uncertain factors, which will impact their mental health as well. Lastly, we will provide possible solutions and suggestions to support college students to improve their psychological problems.

\section{LITERATURE REVIEW}

During the COVID-19, a significant number of college students are experiencing lockdown and remote learning problems. It might bring a negative effect on their mental health. COVID-19 is a global disease, which has a high infection rate. In order to prevent and control 
the epidemic, countries are carrying out national closure and lockdown. This action has dramatically changed the way of life and learning of college students and affected their mental condition. The data shows that national closure has impacted more than $91 \%$ of the world's student population [5]. Therefore, with the spread of the virus in various countries, and the closure of various universities and colleges, more than $80 \%$ of the world's students cannot go to universities. Most of the colleges adopt remote learning and e-learning to ensure that students could continue their studies. In this way, quarantine life and remote learning will "accompanied by psychological, social and economic consequences", which develop 'negative emotions, confusion and pessimism' [5]. A number of students in the lockdown have shown a negative impact on their mental health and psychological condition. Learning through online platforms has led to depression and anxiety disorders of college students. Also, college students' satisfaction is significantly related to the prevalence of depression, anxiety, and stress [6]. Mirna conducts a survey about the satisfaction with online learning during COVID - 19 quarantine, and the results shows that "in total, almost half of the sample and namely $48.65 \%$ of the students, were dissatisfied with the experience, 147 (28.3\%) were neutral and only $23.1 \%$ of the students surveyed were satisfied with e-learning". She also designs a survey for the Depression, anxiety, and stress scale among college students. The result shows that $17.9 \%$ of the students are suffering mild depressive symptoms, while $13.8 \%$ have moderate and $1.7 \%$ have severe depressive symptoms. Andria also raises up a survey which 509 students collected in the questionnaire [6]. Andria uses The SelfAssessment Anxiety Scale and the Depression Scale Epidemiological studies to value the depression symptom. The finding shows that most of the students express that they do not have the chance to go outside and gather with their friends. During the COVID-19, the student's anxiety and depression level have significantly increased. Moreover, the level of depression and anxiety of students in China is "higher than the level of the national norm" [6]. College students are characterized by being prone to stress disorder and depression. Due to the psychological challenges and psychological conditions they face every day, the possibility of this impact is expected to increase during the COVID-19 isolation period. During the isolation period, social isolation and reduced activity can exacerbate the feeling of procrastination and worthlessness. This situation may aggravate anxiety and depression, which is understandable. The screen creates a strong sense of isolation, which makes it difficult for many people to participate. A very special group of college students is international students. They face more psychological challenges than ordinary college students. The negative impact of lockdown and remote learning on international students is even more remarkable. Many international students left their hometown and are trapped abroad for lockdown because of the epidemic. They are alone in foreign countries and have no communication partners. They also receive heavy academic pressure, which will increase the possibility of depression as well.

In addition, the impact of racism on the mental health of college students cannot be ignored. Unlike remote learning and economic pressure, the victims of racism are mainly concentrated in Asian and African communities. In December 2019, COVID-19 was first detected in Wuhan, China. As the epidemic spreads rapidly around the world, transnational ethnic health challenges and national politics have exacerbated racism and xenophobia. Some media began to use the "Chinese virus" to describe COVID-19. Charissa's research shows that $75 \%$ of Asian/Asian immigrants have experienced discrimination during the pandemic [7]. As the largest group of international students, Asian students have become the main victims of "anti-asian".

This kind of racial discrimination against Asia has a direct negative impact on mental health. Lee et al(2021)'s study points out that more than $40 \%$ of Asian victims have reported increased depressive symptoms and sleep difficulties, and show physical symptoms to a certain extent [8]. From the perspective of the medical environment, data from another research show that compared with other populations, black and Asian minority communities and immigrants have higher mortality rates and receive less medical help [9]. The Freud incident that occurred at the same time caused a worldwide "Black lives matter" parade, crowds gathering leading to a high risk of infection. The spread of the epidemic caused by potential racism in the health system and BLM demonstrations has aggravated the panic in the community and increased the negative sentiment caused by COVID-19 [10]. Another data on adolescents of various ethnic groups in the United States shows that black adolescents are far less likely to receive psychotherapy than white adolescents, and the suicide attempt rate and suicide rate of black adolescents are also on the rise during the epidemic [11]. In general, racism has a significant negative impact on the mental health of yellow and black students, and it is a problem that needs to be discussed and resolved.

COVID-19 puts financial pressure on college students and gradually affects their mental health. With the pandemic, economic recession results in many families lose their income source. About how to pay the tuition fee, more students feel depressed and anxious [12]. However, part-time work for students has dried up in the United States [13]. Although some students can still earn full salary when campuses closed, many students who rely on the employment from school or off campus find themselves without a source of income. In Australia, Australian Prime Minister Scott Morrison asked overseas students to go back home. By this time, most international students lost their jobs and can't afford to 
leave Australia [14]. Except for this, international students were excluded from federal and state government relief packages and were refused to provide income support [15]. These financial difficulties mean many international students could not afford fundamental rights such as food and shelter [16]. One of the students said, "I have enough money for food and rent this weekend, but my boss wants to see me tomorrow. I'm scared I will lose my job." The following student said, "Our countries expect us to work in Australia and support ourselves, but I've lost all my three jobs. I don't know what to do." These two voicings are both from helpseeking students who have described their feelings of shame, stigma, and fear. It is obvious that these two students may meet difficulties in mental health. According to the current research to determine the prevalence of self-reported mental health symptoms and associated factors, Wathelet and colleagues asked all French universities to send an email to their students for completing an online questionnaire [17]. 69054 university students finished the questionnaire, most of whom were women $(72.8 \%)$ and first-year students (47\%). Results show many rates, especially $11.4 \%$ suicidal thoughts and $16.1 \%$ severe depression.

\section{DISCUSSION}

As mentioned above, COVID-19 has a significant negative impact on the mental condition of college students. Therefore, discussing solutions is of great significance to college students' mental health and daily functions (learning efficiency, living conditions, etc.). In the following paragraphs, the authors will propose and evaluate possible improvement plans based on the three perspectives of school, society, and individuals, and discuss the future direction of the pandemic response.

\section{1. "Telepsychiatry" and Helps from the Society}

By 2020, more than half of the world's population will be locked down due to the epidemic, and college students, especially international students, will be affected by lockdown even more [18]. In order to reduce the negative impact of the pandemic on college students and promote their mental condition, a number of social organizations provide various mental health services for students affected by COVID-19, and some government/healthcare system policies can also be effective for college students' well-being.

Telepsychiatry can be defined as a kind of online assistance provided by social organizations and medical personnel, including telephone intervention, video conferencing, online diagnosis, etc. In the context of widespread lockdown caused by COVID-19, Telepsychiatry is a promising and growing way to deliver mental health service [19]. Many social and official mental health organizations provide remote services, such as the world's largest suicide intervention, "Lifeline", has created a peer psychological organization for teenagers to improve their mental health in the form of regular online gatherings, meeting peers, and giving lectures. Similarly, JED, a youth mental health advocacy and suicide intervention organization, has led a campus project to improve mental health resources by collaborating with more than 300 colleges and universities [19]. In addition, some hospitals and psychological counseling institutions have also joined forces with the government to establish an online counseling platform. College students can talk or treat mental health workers through video conferences without going out. Telepsychiatry has significant advantages in improving the mental health of college students. Studies have shown that compared to offline meetings or treatments, some patients report that they feel "more comfortable" and "safer" when discussing difficult topics using online devices [20]. Also, for college students who need to attend classes, the telepsychiatry line Going up activities saves time spent on the road, so the schedule is more flexible [21].

For the group of college students severely affected by COVID-19, mental health testing is no less important than COVID testing. Cindy (2021) [22] pointed out that the government can test the mental health conditions of key populations while increasing the progress of COVID testing, so as to increase the detection rate of mental illnesses and reduce the number of patients who are not diagnosed in time due to the epidemic. Another policy is to open up license restrictions for psychotherapy. The State of Texas in the United States first passed a law that allows unlicensed psychologists to participate in the mental health system to provide low-cost treatment for people in need [23]. The simultaneous implementation of the two policies will significantly improve mental health's detection rate and provide more psychological counseling opportunities. However, to implement this method, the government needs to provide necessary psychologists and testers with funds and necessary protective measures. Also, ensuring the professionalism of the treatment staff is also a huge challenge during the epidemic.

In addition, many other policies on the mental health of college students have also been implemented in their lives. The United States, the United Kingdom, Australia, and many other countries provide local students with rental subsidies and purchase subsidies. Students can receive a large number of subsidies based on their rental certificates and purchase records, which may alleviate the negative mood caused by the economy [24]; at the same time, some Social organizations also cooperate with schools to mobilize volunteers to provide students with food and club activities. As the backbone of the fight against mental illness, society and government can significantly improve the negative emotions of college students. 


\subsection{Grade Policy and Financial Support from College}

During COVID-19, the school can also do something to help students get out of depression. Some students have depression trend feel depressed in their study life because they must take the online course and are likely to meet difficulty in adapting to the online course. The first perceptive is about the professors in the university. Professors can adjust course difficulty or delete some parts of course content to alleviate students' pressure. For example, Professor Julie Libarkin at Michigan State University (MSU, in the USA) has already taken action in her course "Global Change." Dr. Julie Libarkin wrote a letter in the syllabus to tell students that pandemic makes a stressful time, and she would reduce the number of assignments and give redo assignments to take less stress to students. After this course adjustment, students at MSU feel less pressure on this course. Many teachers can take action, as Dr. Julie Libarkin. The second way is about students' grades. Many schools begin to carry out the policy of Pass or Fail, a binary grading system, meaning that no letter grade will be recorded on students' college transcript [25]. It allows all final grades of A, B, and $\mathrm{C}$ (and, in some schools, D) to be weighed as a "Pass." To some extent, this binary grading system alleviates students' stress. When students meet problems in internet connection or learning material, thus grades dropped, they can own a chance to remedial their GPA. Due to the coronavirus pandemic, Michigan State University started to offer the Satisfactory/Not Satisfactory (S/NS) binary grade reporting option to students in the Fall 2020 semester and Spring 2021 semester [26]. For undergraduate students, the threshold between S and NS will be 1.0 [26]. Many other schools have carried out Satisfactory/Unsatisfactory grades, such as John Hopkins University. On the academic transcript, students who earn a grade of $\mathrm{C}$ - or above in a $\mathrm{S} / \mathrm{U}$ course receive Satisfactory credit, and a mark of S is entered on the academic record [27]. The third way is about offering financial support by the university during COVID-19. Some students who lost their job during COVID-19 may feel depressed about paying their tuition. Some schools can give financial support to students for tiding over difficulties. For example, The Coronavirus Response and Relief Supplemental Appropriations Act (CRRSAA) has allocated an additional \$37.4 million in COVID-related aid to NYU [28]. NYU opted to commit \$24.6 million directly to students as financial support. Every NYU student can $\log$ in to the specific website to apply for $\$ 2000$. University of Washington (UW) is eager to help the students whose parent(s) are experiencing a change in their financial situation due to COVID-19. On 1st May 2020, UW promised to give students with financial needs $\$ 1700$ in coronavirus aid [29]. International students, non-matriculated students, students involved in distanceonly degree programs, and undocumented students are all ineligible for a grant. UW has Emergency Aid to support currently enrolled UW students who are sunk into stress from unexpected costs and needs [30]. To some extent, the economic support from universities can help students reduce their financial pressure. The fourth way is about psychological help from college. College can provide counseling or psychiatric services to students. Counseling of this service can help students relieve their stress. For example, MSU provides a relevant service called Counseling and Psychiatric Staff (CAPS), available 24/7 [31]. Due to COVID-19, CAPS can help students remotely. When students need someone to talk to right now, they can call crisis services anytime. MSU is trying to help every depressed student to get out of depression.

\subsection{Dealing with Depression by Self-adjustment and Aids from Close Relationships}

The lockdown, racism, and economic difficulties may make college students feel depressed. They can ask for college and society for help and need to try to deal with negative emotions by themselves and the people around them. It is essential to direct yourself when you feel depressed, during the lockdown, or isolated from social networking. There are several ways to adjust their mood and ease their pain. One of the most effective ways during the lockdown to reduce such depression and provide a way for relaxation can be Music therapy. Aalbars suggests that music therapy contains "the professional use of music and its elements as an intervention in a medical, educational, and everyday environment with individuals, groups, families, or communities, who seek to optimize their quality of life and improve their physical, social, communicative, emotional, intellectual and spiritual health and well-being" [32]. Under that condition, music therapy is a very effective way to deal with a depressed mood. It becomes a healer for depression and can improve people's mental health during the lockdown. The COVID-19 and lockdown have tormented depression among youngsters, which includes college students. Madhurima from Adamus University makes the point that the form of music that patients can choose will be listed as follows. Firstly, she holds the idea that people who suffer from negative moods can listen to "soft melodious music". Secondly, for college students and young people, they can listen to jazz and rock for a suitable time. Thirdly, it is not a good choice for listening to a sad song or the song that makes people feel melancholy. Fourthly, people can benefit from listening to classical music for relaxation. Lastly, the listener might try his/her best to prevent any negative thoughts from lingering in his/her mind, which may be harmful to physical and mental health. Madhurima explains that all people can receive benefits from music therapy during the lockdown. Because it provides them a way of evocation and relaxation, healing the pain from depression and anxiety, and reduces seclusion that prevents them from being alone during the lockdown [32]. 
Self-regulation is also an important way to relieve depressed feelings. Lawrence and Melinda in their article Dealing with Depression During Coronavirus suggest that college students can distract themselves when they feel negative emotions [33]. By doing so, they can focus on something else that makes them interested and make their life meaningful. For example, learning a new instrument or writing a novel. These actions can make them break from those negative thoughts and worries. Also, students can do some simple exercise outside the room for relaxation. As a result, regular exercise can be seen as antidepressant medication in relieving depression or depressed thoughts. It is also an effective way to boost one's mood and feel relieved and relax. Additionally, students can find a simple source of joy in their daily life. For example, spend time with pets and friends, watch some fun videos that make people laugh, or eat some delicious food, and so on. In this way, college students can achieve a comfortable and pleasant mental condition through their own efforts and self-regulation [33]. In addition to music therapy and self-regulation, college students can also seek help from their friends and families. Danielle Dresden suggests that friends and families can listen to their concerns and accompany them when they feel depressed. Their close friends or family members make them feel comfortable, relaxed, calm, and unrushed. They also can "explain the different circumstances that are causing concern" to the students [34]. College students who are suffering from depression are never alone. They can receive help and support from their school, society, government, close friends, families and adjust their mood by themselves.

\section{CONCLUSION}

In conclusion, the COVID-19 has crowded out other influenza viruses to come, that is, the domestic virus worldwide. In the context of the lockdown, private institutions and institutions of higher education are most affected. These institutions have to stop activities and change classes from face-to-face to online. This epidemic has led to many challenges for college students in remote learning, which leads to more cases of depression among students. Students who suffer from depression for a long time do not perform well in academic performance and stress management, and are more likely to suffer from depression, which may negatively affect individuals and society. This paper focuses on the causes and countermeasures of depression in college students during the epidemic. There are three main reasons for college students' depression. Firstly, a large number of college students are facing the problems of lock-in and distance learning. Such a relatively closed learning environment will have a negative impact on their mental health. Secondly, racism for Asian students and African students will also make students have psychological burdens and negative emotions. Thirdly, with the pandemic, the recession has caused many families to lose their source of income. This will make students worry about their financial conditions, including tuition fees and lack of living expenses. For these problems, we propose and evaluate possible improvement plans based on three perspectives of school, society, and individuals, and discuss the future direction of pandemic response. For government and society, some social organizations provide various mental health services for students affected by COVID-19. Some government/medical system policies can also effectively promote the health of college students. As for the efforts of schools, they adjust the examination policy and teaching methods to reduce the burden and psychological pressure on students, set up a well-being center for students to solve psychological problems promptly, and provide students with scholarships to help with their economic conditions. In the context mentioned above, we also discuss that selfadjustment and the help from people's close relationships could also effectively alleviate the negative emotions during the lockdown period. In the future, in order to better solve the negative impact during the epidemic, a more comprehensive epidemic management system should be established. This can make people feel safer and speed up to fight against the epidemic. Moreover, more research on the epidemic and mental health can be developed. It serves to help more people who are troubled by negative emotions during the epidemic.

\section{REFERENCES}

[1] Strauss, V. (2020). Schools of more than 90 percent of the world's students closed during this pandemic. This graphic shows how fast it happened. The Washington Post. https://www.washingtonpost.com/education/2020/0 4/06/schools-more-than-90-percent-worldsstudents-closed-during-this-pandemic-this-graphicshows-how-fast-it-happened/.

[2] M. Billy,. (2019) The Influence of Dynamic Organizations and the Application of Digital Innovations to Educational Institutions in the World during the COVID. https://papers.ssrn.com/sol3/papers.cfm?abstract_id $=3588233$

[3] W, Cao,. Z, Fang,. G, Hou,. M, Han,. X. Xu,. J, Dong,(2020) "The psychological impact of the COVID-19 epidemic on college students in China," Psychiatry Res., vol. 287.

[4] Charissa S.L. Cheah, Cixin Wang, Huiguang Ren, Xiaoli Zong, Hyun Su Cho, Xiaofang Xue(2020) COVID-19 Racism and Mental Health in Chinese American Families,146 (5) e2020021816; DOI: 10.1542/peds.2020-021816

[5] Pragholapati, A. (2020). COVID-19 IMPACT ON STUDENTS. https://doi.org/10.35542/osf.io/895ed. 
[6] Fawaz, M., \&amp; Samaha, A. (2020). E-learning: Depression, anxiety, and stress symptomatology among Lebanese university students during COVID - 19 quarantine. Wiley Online Library. https:/onlinelibrary.wiley.com/doi/full/10.1111/nu f.12521.

[7] Charissa S.L. Cheah, Cixin Wang, Huiguang Ren, Xiaoli Zong, Hyun Su Cho, Xiaofang Xue(2020) COVID-19 Racism and Mental Health in Chinese American Families,146 (5) e2020021816; DOI: 10.1542/peds.2020-021816

[8] Lee, S., \& Waters, S. F. (2021). Asians and Asian Americans' experiences of racial discrimination during the COVID-19 pandemic: Impacts on health outcomes and the buffering role of social support. Stigma and Health, 6(1), 70-78. https://doi.org/10.1037/sah0000275

[9] Johnson-Agbakwu, C.E., Ali, N.S., Oxford, C.M. et al. Racism, COVID-19, and Health Inequity in the USA: a Call to Action. J. Racial and Ethnic Health Disparities (2020). https://doi.org/10.1007/s40615020-00928-y

[10] Jackson C, Newall M, Yi J. Significant Racial Disparities Exist in Knowing Someone Who Has Died From COVID-19. Ipsos. May 22, 2020. Accessed September 6, 2020. https://www.ipsos.com/en-us/news-polls/abccoronavirus-poll-wave-10

[11] Price JH, Khubchandani J. The Changing Characteristics of African-American Adolescent Suicides, 2001-2017. J Community Health. 2019;44(4):756-763.

[12] L. Peng, J. Zhang, M. Li, P. Li, Y. Zhang, X. Zuo, Y. Miao, Y. Xu Negative life events and mental health of Chinese medical students: the effect of resilience, personality and social support Psychiatry Res., 196 (1) (2012), pp. 138-141

[13] Writers, S. (2020). Update on the College Student Mental Health Crisis: BestColleges. BestColleges.com.

https://www.bestcolleges.com/blog/mental-healthin-college-students-during-covid-19-mental-healthcrisis.

[14] Gallagher, H. L., Doherty, A. Z., \& Obonyo, M. (2020). International student experiences in Queensland during COVID-19. International Social Work, $63(6)$ 815-819. https://doi.org/10.1177/0020872820949621

[15] Karp, P. (2020) 'Australian Universities Warn Covid-19 Relief Package Not Enough to Stop 21,000 Job Losses', The Guardian, 12 April.
Available

online

at:

https:/www.theguardian.com/australianews/2020/apr/12/australian-universities-warncovid-19-relief-package-not-enough-to-stop21000-jobs-losses

[16] Jeffrey, C. (2020) 'Students Are the Generation Most Affected by Covid-19: Universities Must Respond'. Available online at: https://www.timeshighereducation.com/blog/stude nts-are-generation-most-affectedcovid-19universities-must-respond .

[17] Gramigna, J. (2020). University students at significant risk for mental health effects of COVID19 lockdown. Healio. https://www.healio.com/news/psychiatry/20201023 /university-students-at-significant-risk-for-mentalhealth-effects-of-covid19-lockdown.

[18] Sandford, A. (2020). Coronavirus: Half of humanity on lockdown in 90 countries call for confinement. Euronews.

from https://www.euronews.com/2020/04/02/coronaviru s-in-europe-spain-s-death-toll-hits-10-000-afterrecord-950-new-deaths-in-24-hou.

[19] Francesco, D,. Antonella, S,. Elena, P,. Mauro, P, Federica, V,. Valeria, V., Giovanni, m,. Massimo, G. (2020) Telepsychiatry and other cutting-edge technologies in COVID-19 pandemic: Bridging the distance in mental health assistance. THE INTERNATIONAL JOURNAL OF CLINICAL PRACTICE. DOI: 10.1111/ijcp.13716

[20] Richardson LK, Frueh BC, Grubaugh AL, et al. Current directions in videoconferencing tele-mental health research. Clin Psychol (New York) 2009; $16: 323-338$

[21] Cowan KE, McKean AJ, Gentry MT, et al. Barriers to use of telepsychi[1]atry: clinicians as gatekeepers. Mayo Clin Proc. DOI: 2019;94:2510-2523

[22] Cindy, B., Elizabeth, S., Daniele, F. (2021), Five Urgent Public Health Policies To Combat The Mental Health Effects Of COVID-19. HealthAffairs. DOI:

\subsection{7/hblog20210122.959001}

[23] Matthew, G., Benjamin, D., Marcela, H., Grayson, N., Kristin, P., Amy, B., Heath, H., Brian, H., Shea, J., Marvin, S., Lisa, D. (2020). Mental Health Policy in the Era of COVID-19. Psychiatric Services. DOI: https://doi.org/10.1176/appi.ps.202000219

[24] https://www.consumer.vic.gov.au/resources-andtools/international-students 
[25] Alcid, A. (2020). What You Need to Know About the Pass/Fail Grading System. Colleges of Distinction.

https://collegesofdistinction.com/advice/what-youneed-to-know-about-the-pass-fail-grading-system/.

[26] S/NS Grade Reporting. S/NS Grade Reporting | MSU Guide to Remote Access | Michigan State University. (n.d.). https://remote.msu.edu/gradingoption/index.html.

[27] Grading Policies. Grading Policies < Johns Hopkins University. (2020). https:/ecatalogue.jhu.edu/engineering/full-time-residentialprograms/undergraduate-policies/academicpolicies/grading-policies/.

[28] Communications, N. Y. U. W. (2020). Student Financial Support. NYU. https://www.nyu.edu/life/safety-healthwellness/coronavirus-information/information-forstudents/student-financialsupport.html\#: :text=Providing\%20support\%20to $\% 20$ students $\% 20$ has,priorities $\% 20$ since $\% 20$ COVI D $\% 20$ first $\% 20$ struck.\&text $=$ Now $\% 2 \mathrm{C} \% 20$ The $\% 20$ Coronavirus $\% 20$ Response $\% 20$ and,million $\% 20 \mathrm{go} \%$ 20directly $\% 20$ to $\% 20$ students.

[29] Daily, E. S. T., \& photo, F. (2020). UW will give single students with financial need $\$ 1,200$ in coronavirus aid. The Daily of the University of Washington.

https://www.dailyuw.com/news/article_7ecf0b28883c-11 ea-8f80-7f235ced20ae.html.

[30] Emergency

Aid.

(2021). https://www.washington.edu/emergencyaid/.

[31] CAPS Services During COVID-19. CAPS Services During COVID-19 | Counseling \& Psychiatric Services | Michigan State University. (2020). https://caps.msu.edu/covid19.html.

[32] Dasgupta, M., MUSIC THERAPY: A HEALER FOR DEPRESSION AND A MEANS TO IMPROVE SOCIAL HEALTH DURING LOCKDOWN. Adamas University. (2020, June 20). http://adamasuniversity.ac.in/music-therapy-ahealer-for-depression-and-a-means-to-improvesocial-health-during-lockdown/.

[33] Weber, M. (2021). Dealing with Depression During Coronavirus. HelpGuide.org. https://www.helpguide.org/articles/depression/deali ng-with-depression-during-coronavirus.htm.

[34] Dresden, D., MediLexicon International. (n.d.). How to care for someone with depression during the COVID-19 pandemic. Medical News Today. https://www.medicalnewstoday.com/articles/howto-care-for-someone-with-depression\#tips. 